1982

\title{
A Critique of the Analytical Methods Used in Examining Decomposition Data Obtained From Litter Bags
}

R. Kelman Wider

Gerald E. Lang

Follow this and additional works at: https://researchrepository.wvu.edu/faculty_publications

\section{Digital Commons Citation}

Wider, R. Kelman and Lang, Gerald E., "A Critique of the Analytical Methods Used in Examining Decomposition Data Obtained From Litter Bags" (1982). Faculty Scholarship. 27.

https://researchrepository.wvu.edu/faculty_publications/27 


\title{
A Critique of the Analytical Methods Used in Examining Decomposition Data Obtained From Litter Bags
}

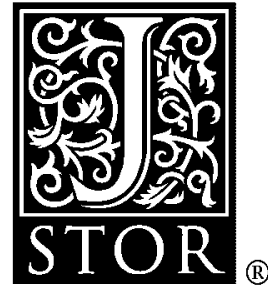

\author{
R. Kelman Wider; Gerald E. Lang \\ Ecology, Vol. 63, No. 6 (Dec., 1982), 1636-1642.
}

Stable URL:

http://links.jstor.org/sici?sici=0012-9658\%28198212\%2963\%3A6\%3C1636\%3AACOTAM\%3E2.0.CO\%3B2-3

Ecology is currently published by The Ecological Society of America.

Your use of the JSTOR archive indicates your acceptance of JSTOR's Terms and Conditions of Use, available at http://www.jstor.org/about/terms.html. JSTOR's Terms and Conditions of Use provides, in part, that unless you have obtained prior permission, you may not download an entire issue of a journal or multiple copies of articles, and you may use content in the JSTOR archive only for your personal, non-commercial use.

Please contact the publisher regarding any further use of this work. Publisher contact information may be obtained at http://www.jstor.org/journals/esa.html.

Each copy of any part of a JSTOR transmission must contain the same copyright notice that appears on the screen or printed page of such transmission.

JSTOR is an independent not-for-profit organization dedicated to creating and preserving a digital archive of scholarly journals. For more information regarding JSTOR, please contact support@ jstor.org. 


\title{
A CRITIQUE OF THE ANALYTICAL METHODS USED IN EXAMINING DECOMPOSITION DATA OBTAINED FROM LITTER BAGS ${ }^{1}$
}

\author{
R. Kelman Wieder and Gerald E. Lang \\ Department of Biology, West Virginia University, Morgantown, West Virginia 26506 USA
}

\begin{abstract}
The study of plant litter decomposition in terrestrial ecosystems commonly employs litter bags to compare the loss of mass among species, among sites, and under various experimental manipulations, or to investigate the process itself. Analysis of the resulting data is quite variable among investigators, and at times inappropriate. Two general analytical approaches to the examination of decomposition data are reviewed. Analysis of variance is useful if the intent is to compare treatment means, but does not directly test hypotheses regarding decomposition rates. If the intent is to determine rate constants, then fitting mathematical models to data is the more appropriate analysis. Single and double exponential models best describe the loss of mass over time with an element of biological realism.

Key words: analysis of variance; decomposition; exponential models; linear models; litter bags; power models; quadratic models.
\end{abstract}

\section{INTRODUCTION}

The investigation of decomposition is an important aspect of the analysis of ecosystem function. Decomposition in terrestrial ecosystems is commonly studied using the litter bag method, which consists of enclosing plant material of known mass and chemical composition in a screened container. Initially, a large number of bags is placed in the field and at each subsequent sampling date a randomly chosen set of bags is retrieved and analyzed for loss of mass and/or changes in the chemical composition of litter. Although the litter bag method is often attributed to Bocock and Gilbert (1957) or to Bocock et al. (1960), the principle of confining known amounts of litter in order to follow its decomposition had been used much earlier (Falconer et al. 1933, Lunt 1933, 1935, Gustafson 1943). Despite several drawbacks (cf. Witkamp and Olson 1963, Wiegert and Evans 1964, Witkamp and Crossley 1966, Ewel 1976, St. John 1980), the litter bag method remains the most commonly used technique for examining litter decomposition in terrestrial ecosystems. Although the method may underestimate actual decomposition, it is assumed that the results of litter bag studies will reflect trends characteristic of unconfined decomposing litter, and as such allow for comparisons among species, sites, and experimental manipulations.

Although there exists a similarity in design and methodology of litter bag studies, considerable variation occurs in the statistical procedures used to examine decomposition data. Two analytical approaches are commonly used: to compare treatment (e.g., species, site) means by some parametric statistical procedure, or to obtain mathematical descriptions of the data that characterize the observed changes over time. These two approaches are conceptually quite

\footnotetext{
${ }^{1}$ Manuscript received 23 September 1981; revised 18 February 1982; accepted 18 March 1982.
}

different; their use depends on the specific objectives of a particular study. In this paper, we review each approach for analyzing decomposition data, discussing relative merits and disadvantages, as well as potential problems of interpretation.

\section{USing ANALysis of VARIANCE to EXamine DECOMPOSITION DATA}

It is often of interest to compare the decomposition of one species in several sites, of several species in one site, or of one species in one site under different experimental conditions such as variable mesh size of the litter bag. The objective of such comparative studies is to assess the effects of treatments (sites, species, experimental conditions) by examining differences among treatment means in the proportion of original mass remaining at various times. Statistical procedures are invoked to assess objectively the significance of these differences among treatment means.

The most commonly used statistical method of examining decomposition data is the analysis of variance, completely randomized design. This design includes a factorial arrangement of treatments, where one treatment is date and others may be site, litter type, etc. (Curry 1969, Ewel 1976, Brinson 1977). The analysis usually is performed on the proportion or percent of the initial amount of $X$ remaining at time $t$, where $X$ may be dry mass, ash-free dry mass, or a given elemental content. Values for time $=0$ are not included in the analysis of variance since for all treatments at time $=0$ the mean percent remaining is 100.0 .

To simplify the following discussion, consider as an example the experimental situation where the decomposition of litter from three different species is simultaneously examined in one site. The corresponding analysis of variance will contain main effects of date and species, and a date $\times$ species interaction. It is only 
when this interaction is nonsignificant (or significant but considerably lower in magnitude than the main effects, Snedecor and Cochran 1978) that the significance of the main effects can be unambiguously interpreted (Appelbaum and Cramer 1974). If the interaction is significant, any inferences about decomposition must be based on a closer examination of the individual cell means.

While it is often desirable to make inferences regarding differences in decomposition rates based on the outcome of an analysis of variance, it is necessary to define the term "decomposition rate." If the variable $X=f(t)$ represents the proportion of initial mass remaining at time $t$, then we will refer to the first derivative of $X$ with respect to $t,(d X / d t)$, as the absolute decomposition rate, which characterizes the slope of the plot of $X$ as a function of time. When the absolute decomposition rate is expressed as a fraction of the remaining mass, the relative decomposition rate $[(d X) /$ $(d t \cdot X)]$ is obtained. Although the analysis of variance does not directly test hypotheses about either absolute or relative decomposition rates, inferences about decomposition rates can be justified if and only if the interaction term is nonsignificant. For instance, in our example, if a nonsignificant interaction is accompanied by a nonsignificant species effect, then there are no differences among the three species in mean percent mass remaining across all sampling dates. It is then reasonable to conclude that over the entire course of the study, i.e., from time $=0$ through the final sampling date, inclusive, the three species decompose at approximately the same absolute rate and at approximately the same relative rate.

If a significant species effect accompanies a nonsignificant interaction (regardless of the significance of the date effect), then at least two of the three species differ in mean percent mass remaining, and the magnitude and direction of this difference is approximately the same across all sampling dates. This condition is illustrated by the hypothetical data in Fig. 1A, where a significant date effect is indicated. In this case, the conclusion would be that between the first and final sampling dates, inclusive, the three species decompose at approximately the same absolute rate, i.e., the slopes of the three plots are about equal. The existing differences in mean percent mass remaining resulted from decomposition that took place between time $=0$ and the first sampling date. Inferences about differences between species in absolute decomposition rates over the entire course of the study will be made with a subjective interpretation of the data and will not be undeniably supported by the results of an analysis of variance. With regard to relative decomposition rates, however, a nonsignificant interaction and a significant species effect indicate differences between at least two of the three species. In Fig. 1A, the relative decomposition rate is lowest for species $X$ and greatest for species $Z$. Inferences about relative decomposition rates are logically extended to cover the entire course of decomposition.

When the interaction is significant, the magnitude and/or direction of differences among species in mean percent mass remaining is not the same across all sampling dates. This condition is illustrated for three different hypothetical outcomes in Figs. 1B, 1C, and 1D. In Fig. 1B, species $Z$ shows an initial rapid loss of mass followed by a very slow loss of mass. Between the first and final sampling dates, species $Y$ loses more mass than either species $X$ or $Z$. In Fig. 1C, on the first three sampling dates percent mass remaining follows the order $X>Y>Z$, whereas on the last three sampling dates the order is reversed so that $Z>Y>X$. The three curves in Fig. 1D cross each other several times over the course of the study. The experimenter must evaluate the significance or nonsignificance of the species effect in light of a relatively subjective interpretation of the nature of the significant interaction. Any conclusion regarding differences in the absolute or relative rates of decomposition among species will be based on this subjective interpretation and will not be definitively supported by the analysis of variance.

If the objective of a particular study is to assess the effect of various treatments on litter decomposition by examining differences among treatment means across all sampling dates, then the analysis of variance may be appropriate. However, considerable care should be exercised when making inferences about decomposition rates. Even when used in this context, the power of the analysis of variance is influenced by how well the underlying assumptions of independent, random sampling, normality of distributions, and homogeneity of variance of error terms are met. The last assumption is crucial. If the assumption of homogeneity of error terms is not met, the actual $\alpha$ level may deviate considerably from the designated $\alpha$ level, thereby diminishing the validity of the analysis (Box 1954).

\section{Fitting Decay Functions to Mass Values}

The second general approach to the analysis of decomposition data is the fitting of mathematical models to estimate constants that describe the loss of mass over time. This approach can be of considerable value for obtaining insights into the biology of the decomposition process, insights which are not obtainable through the statistical procedures discussed previously. Here we review the models commonly used to examine decomposition data (see Table 1), discussing both the mathematical properties of the models and the relationships between the models and the biology of litter decomposition.

The most frequently used model to describe decomposition is the single exponential decay function, first proposed by Jenny et al. (1949) and discussed in considerable detail by Olson (1963). The appeal of this exponential model arises from the fact that a single constant, $k_{s e}$, characterizes the loss of mass, thereby 


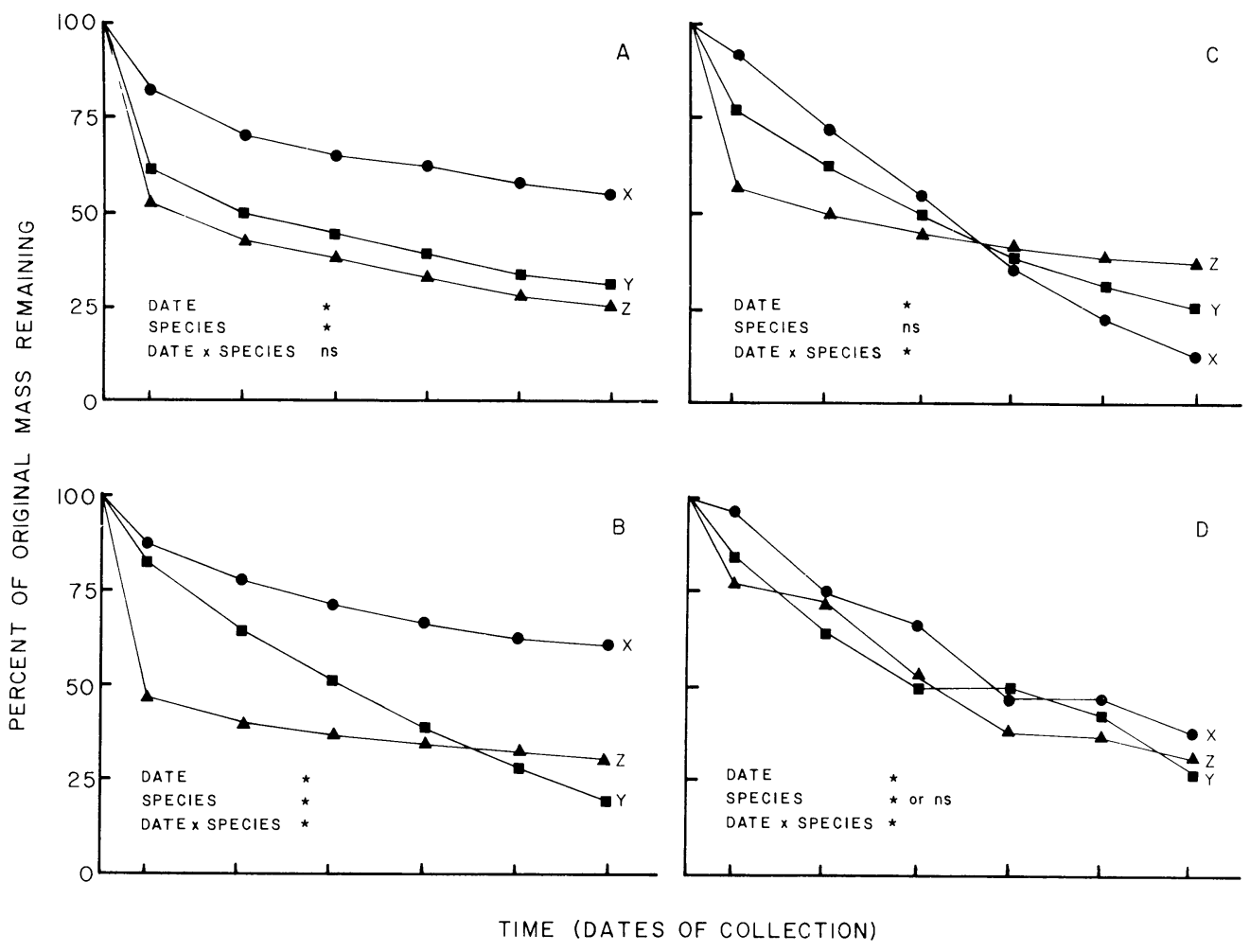

FIG. 1. Hypothetical results from a decomposition experiment using three species of litter (X, Y, and Z) confined within litter bags. * indicates a significant effect based on the analysis of variance; a nonsignificant effect is indicated by ns. The abscissa represents the time course for the experiment with collection dates indicated by tick marks.

facilitating comparisons with other data sets and simplifying attempts to model the accumulation of organic carbon in soils (e.g., Olson 1963, Oohara et al. 1971). The assumption underlying the single exponential model can be expressed in two ways: either the absolute decomposition rate decreases linearly as the amount of substrate remaining declines, or the relative decomposition rate remains constant (Table 1). Intuitively, this assumption corresponds well with our knowledge and understanding of the biology of litter decomposition. As decomposition proceeds, soluble components and relatively easily degraded compounds such as sugars, starches, and proteins will be rapidly utilized by decomposers, while more recalcitrant materials such as cellulose, fats, waxes, tannins, and lignins will be lost at relatively slower rates. Thus, with time the relative proportion of these recalcitrant materials will progressively increase and the absolute decomposition rate should decrease, while the relative decomposition rate may remain constant.

Because of the two-step nature of decomposition dynamics the single exponential decay model has been modified to the double exponential decay model (Table 1). The double exponential decay model assumes that litter can be partitioned into two components, a relatively easily decomposed or labile fraction $(A)$, and a more recalcitrant fraction $(1-A)$. Each fraction decays exponentially at rates characterized by $k_{1 d}$ and $k_{2 d}$, respectively; total decomposition is represented by the sum of the losses from each fraction. The proportion of $A$ to $(1-A)$ is a characteristic attributed to initial, undecomposed litter. The double exponential model does not consider any possible transfer of labile to recalcitrant material, as may occur in the synthesis of microbial biomass during decomposition. The double exponential decay function represents a mathematical compromise between the single exponential function and the ideas of Minderman (1968), who suggested that each of several fractions of fresh litter would decompose exponentially and that the total decomposition should be represented by the sum of the individual fractions.

The asymptotic model is closely related to both the single exponential and double exponential models (Table 1). The asymptotic model can be thought of as the single exponential model that tends toward a positive constant rather than toward zero, or it can be thought of as the double exponential model where $k_{2 d}$ equals zero, i.e., the recalcitrant fraction is completely resistant to decay. Since no fraction of plant litter is completely immune from microbial attack, the generality of the asymptotic model is questionable. However, 
TABLE 1. Models commonly used to examine decomposition data. Define the variable $X$ as the proportion of initial mass $\left(X_{0}\right)$ remaining at time $t$. Thus, $X=\frac{X t}{X_{0}}$ is defined on the interval $0 \leqslant X \leqslant 1$. The model parameters are: $k$ 's which are decay constants; $C$ 's and $A$ which are other constants. References are: (1) Jenny et al. (1949); (2) Olson (1963); (3) Woodwell and Marples (1968); (4) Van Cleve (1971); (5) Lang (1973); (6) Bunnell and Tait (1974); (7) Howard and Howard (1974); (8) Pal and Broadbent (1975); (9) Lousier and Parkinson (1976); (10) Grigal and McColl (1977); (11) Hunt (1977); (12) Lawrey (1977); (13) Wieder (1978); (14) Wieder et al. (1983).

\begin{tabular}{|c|c|c|c|c|}
\hline Model & Expression & $\begin{array}{l}\text { Absolute decomposition rate } \\
\qquad \frac{d X}{d t}\end{array}$ & $\begin{array}{l}\text { Relative decomposition rate } \\
\qquad \frac{d X}{d t \cdot X}\end{array}$ & References \\
\hline $\begin{array}{l}\text { Single } \\
\quad \text { exponential }\end{array}$ & $X=e^{-k_{s e} t}$ & $-k_{s e} e^{-k_{s e} t}=-k_{s e} X$ & $-k_{s e}$ & $\begin{array}{c}1,2,5,7,9,12 \\
13,14\end{array}$ \\
\hline $\begin{array}{l}\text { Double } \\
\quad \text { exponential }\end{array}$ & $\begin{aligned} X= & A e^{-k_{1 d} t} \\
& +(1-A) e^{-k_{2 d} t}\end{aligned}$ & $-k_{1 d} A e^{-k_{1 d} t}-k_{2 d}(1-A) e^{-k_{2 d} t}$ & $\frac{-k_{1 d} A e^{-k_{1 d} t}-k_{2 d}(1-A) e^{-k_{2 d} t}}{A e^{-k_{1 d} t}+(1-A) e^{-k_{2 d} t}}$ & $6,9,11,13,14$ \\
\hline Asymptotic & $\begin{aligned} X= & C_{a} \\
& +\left(1-C_{a}\right) e^{-k_{a} t}\end{aligned}$ & $-\left(1-C_{a}\right) k_{a} e^{-k_{a} t}$ & $\frac{-\left(1-C_{a}\right) k_{a} e^{-k_{a} t}}{C_{a}+\left(1-C_{a}\right) e^{-k_{a} t}}$ & $7,9,14$ \\
\hline Linear & $X=C_{\ell}-k_{\ell} t$ & $-k_{\ell}$ & $\frac{-k_{\ell}}{C_{\ell}-k_{\ell} t}$ & $3,5,7,10$ \\
\hline Quadratic & $\begin{aligned} X= & C_{q}+k_{1 q} t \\
& +k_{2 q} t^{2}\end{aligned}$ & $k_{1 q}+2 k_{2 q} t$ & $\frac{k_{1 q}+2 k_{2 q} t}{C_{q}+k_{1 q} t+k_{2 q} t^{2}}$ & $5,7,8$ \\
\hline Power & $X=C_{p} t^{k_{p}}, \quad k_{p}<0$ & $C_{p} k_{p} t^{\left(k_{p}-1\right)}$ & $\frac{C_{p} k_{p} t^{\left(k_{p}-1\right)}}{C_{p} t^{k_{p}}}=\frac{k_{p}}{t}$ & $4,7,8$ \\
\hline
\end{tabular}

under certain experimental manipulations or in very harsh environments, the asymptotic model may describe the data quite well for at least the period over which a particular study is conducted. For example, the asymptotic model was proposed by Howard and Howard (1974) in the context of examining the decomposition of leaf litter when fauna were completely excluded. Since the data of Howard and Howard were best described by the asymptotic model, they suggested that in the absence of the faunal component, decomposition will not proceed beyond a certain point. Wieder et al. (1983) obtained double exponential fits characterizing the loss of mass from fescue litter decomposing in tallgrass prairie, vegetated surface mine, and nonvegetated surface mine sites. For the nonvegetated surface mine site only, the double exponential model collapsed to the asymptotic model (i.e., the estimated value for the parameter $k_{2 d}$ was zero), suggesting that the harsh chemical and physical environment of the nonvegetated surface mine site may have excluded or reduced the activity of decomposer organisms, making the recalcitrant fraction of the litter effectively undecomposable by biotic processes.

The respective mathematical behaviors of the single exponential, double exponential, and asymptotic models are quite similar. For all three models the absolute decomposition rate tends toward zero as time progresses (Table 1). The relative decomposition rate is constant for the single exponential model and approaches a constant value $\left(-k_{2, l}\right)$ for the double ex- ponential model as the remaining mass of the labile fraction becomes very small relative to the remaining mass of the recalcitrant fraction. For the asymptotic model, the relative decomposition rate, as originally defined, approaches zero as time progresses. However, if the relative decomposition rate for the asymptotic model is expressed as a fraction of the remaining amount of the initial decomposable mass $\left(1-C_{a}\right)$, then this modified relative decomposition rate also approaches a constant $\left(-k_{a}\right)$.

Other less commonly used models include the linear, quadratic, and power functions. The linear model considers that the absolute decomposition rate is constant throughout decomposition while the relative decomposition rate increases with time (Table 1), assumptions which are difficult to justify biologically. Nonetheless, if a very small quantity of mass is lost over the course of decomposition, a linear function may fit the data quite well, e.g., Woodwell and Marples (1968), and some of the data of Lang (1973) and of Grigal and McColl (1977). Litter that has a small amount of both readily leachable and labile compounds appears to follow a linear model, at least for the first year or two.

In other instances, although decomposition appears to be decidedly nonlinear, good linear fits have been obtained such that the model considerably underestimates early stages of decomposition, overestimates late stages of decomposition, and has a $y$ intercept $\left(C_{\ell}\right.$ in 
Table 1) <1 (e.g., some of the data of Lang [1973] and of Grigal and McColl [1977]). Linear regressions of this type certainly indicate a best fit in terms of least squares analysis. However, if the objective of curvefitting is to obtain estimates of decay constants or to derive empirical expressions for the subsequent modeling of organic matter accumulation, it is imperative that the model be fitted subject to the restriction that at time $=0$ all of the initial litter is present.

Although quadratic and power functions are sometimes used as decomposition models, certain aspects of their respective mathematical behaviors make them less suitable than the exponential models. By the nature of the quadratic function it is often possible to obtain parameter estimates that yield good fits to nonlinear data (Snedecor and Cochran 1978). For decomposition studies, quadratic models may describe the data quite well within the ranges of $X$ and $t$ spanned by a particular data set; however, extrapolation beyond the range of the data can be especially problematical. In particular, as time increases indefinitely, both $X$ and the absolute decomposition rate tend toward positive or negative infinity (depending on the sign of $k_{2 q}$ ), behaviors which are clearly unrealistic with regard to the biology of plant litter decomposition. The mathematical properties of the quadratic model in the limit make it one of the least appropriate for litter decomposition data.

The power function has the mathematically undesirable property of approaching infinity as time approaches zero. Thus it is not possible for the power function to meet the restriction that at time $=0$ the proportion of initial litter remaining is equal to 1.0.

\section{Statistical Consequences}

At this point, it is appropriate to consider some of the statistical consequences associated with different approaches to fitting mathematical models to decomposition data. The models listed in Table 1 can be divided into two groups: those which are linear or intrinsically linear in the parameters, and those which are intrinsically nonlinear in the parameters. Intrinsically linear models can be transformed such that they become linear, whereas intrinsically nonlinear models cannot be converted to a linear form (Draper and Smith 1966). Because the single exponential and asymptotic models are intrinsically linear, they along with the linear model can be fit to decomposition data using linear least squares estimation. Nonlinear least squares estimation should be used in fitting the intrinsically nonlinear models, and may also be used in fitting untransformed single exponential or asymptotic models (see Statistical Analysis System [SAS] 1979 for references).

Quite commonly the linearized (logtransformed) form of the single exponential model is fit to decomposition data. One advantage to this approach is that for a par- ticular study direct statistical comparisons of slopes, intercepts, and residual variances among a series of individual regressions can be made using analysis of covariance techniques (Snedecor and Cochran 1978). It is also possible to test whether each regression line predicts that at time $=0$ all of the initial litter is present (Snedecor and Cochran 1978:166-167). If a regression does not predict that at time $=0$ all of the initial litter is present, it can be inferred that the particular model may not be the most appropriate for describing the observed data, and the meaningfulness and interpretation of comparisons among $k$ values become questionable.

For example, if the data in Fig. 1A are log transformed, then the fixed intercept model (specifying that at time $=0$ all of the initial litter is present) would estimate higher $k$ values than the unfixed intercept model (where the intercept is estimated as a parameter); qualitatively both models would estimate the $k$ value for $Z>Y>X$. Also, for the unfixed intercept model the deviation from predicting that at time $=0$ all of the initial litter is present would be greatest for species $Z$ and least for species $X$. In general, for unfixed intercept models the greater the deviation from predicting that at time $=0$ all of the initial litter is present, the greater will be the discrepancy in estimated $k$ values between fixed and unfixed intercept models for a particular data set.

Although analysis of covariance does provide a method for comparing a series of regression equations, when the method is used to examine decomposition data inferences should be made in light of how well each of the regressions predicts that at time $=0$ all of the initial litter is present. Analysis of covariance is limited to linear or linearized models and cannot be applied to either fixed intercept or intrinsically nonlinear models. We know of no commonly used technique for comparing parameter estimates among a series of either fixed intercept or intrinsically nonlinear regressions.

In modeling decomposition phenomena, expressions are desired that are realistic in terms of both mathematical and biological behavior. Specifically, the mathematical expressions should meet the following requirements: the proportion of initial mass remaining should change as a function of time, i.e., $X=f(t)$; the expression should be monotonically decreasing and continuous; the expression should be bounded by $X=1$ and $X=0$; the absolute decomposition rate should progressively decline; and the relative decay rate should be a constant or tend toward a constant in the limit. While the three exponential models meet all of these requirements, the linear, quadratic, and power models each fail to meet at least one of the requirements. Of the models listed in Table 1, the most realistic, in terms of both mathematical and biological behavior, are the exponential models. 


\section{SOME EXAMPLES}

Although considerable caution must be exercised when inferring process from pattern, we conclude this discussion by relating two instances where the double exponential model has been useful in providing considerable insight into the biology of the decomposition process.

Pinck et al. (1950) examined the decomposition of a wide variety of plant materials in soil at a constant temperature and moisture regime; Hunt (1977) fit the double exponential model to the loss of mass for each litter type. Hunt found that the determined values for $k_{1, t}$ and $k_{2 \prime \prime}$ were fairly uniform across the 10 types of litter examined, suggesting that the decomposition dynamics for the labile $(A)$ and recalcitrant $(1-A)$ fractions, respectively, are quite similar over a wide variety of plant materials. Differences among plant materials in overall decomposition rate were attributed to differences in the relative proportions of the labile and recalcitrant fractions initially present in each type of plant material. A significant, although nonlinear, relationship was also found between the relative initial proportions of labile to recalcitrant fractions and both the initial lignin content and the initial $\mathrm{C} / \mathrm{N}$ ratio. Plant materials with a higher lignin content or a higher $\mathrm{C} / \mathrm{N}$ ratio will have a relatively greater recalcitrant fraction and thus will decompose more slowly than plant materials with a relatively low initial lignin content or a relatively low initial $\mathrm{C} / \mathrm{N}$ ratio. Numerous workers have suggested that initial lignin content (e.g., Cromack and Monk 1975, Fogel and Cromack 1977, Meentemeyer 1978, Melillo et al. 1982) or initial C/N ratio (Jensen 1929, Witkamp 1966, Melillo et al. 1981) may be a reasonable predictor of the rate of decomposition. Hunt's results, however, suggest that the mechanism by which these factors influence the decomposition rate may be through a shift in the relative proportions of labile to recalcitrant fractions, the respective decay rates of which are fairly constant at a given temperature and moisture regime. Thus, given a uniform environment, the process by which decomposition proceeds may be very similar over a wide variety of plant materials, despite considerable differences in overall decomposition rates.

The double exponential model is also particularly useful in the experimental situation where the decomposition of one litter type is simultaneously examined in several sites. It is reasonable to assume that the initial relative proportion of labile to recalcitrant fractions is constant for litter in all bags. If there are $n$ sites, the resulting data can be used to fit a series of $n$ simultaneous double exponential decay equations of the general form

$$
\frac{X_{t j}}{X_{0 j}}=A e^{-k_{1 j} t}+(1-A) e^{-k_{2 j} t}, \quad j=1,2 \ldots n
$$

where the $k_{1 j}$ and $k_{2 j}$ are the decay constants which characterize the losses of the labile and recalcitrant fractions, respectively, in the $j^{\text {th }}$ site. If differences in the loss of mass among sites do exist, they will not be due to differences in the initial relative proportion of labile to resistant fractions, but rather must be the result of site differences which control the differential rates at which these fractions decompose (Wieder 1978, Wieder et al. 1983).

The prevailing use of statistics as a research tool is commonplace. Statistical analyses, however, only provide an objective way of examining data and should be used to help interpret the results of a particular study. As such, understanding the limitations and disadvantages of a particular statistical procedure is requisite to proper interpretation of real data.

\section{ACKNOWLEDGMENTS}

This work was supported by a grant (DEB 79-07346) from the National Science Foundation. We thank Drs. K. Cromack, Jr., G. R. Hobbs, H. W. Hunt, J. E. Means, L. H. Rose, and J. B. Waide for their critical readings of the manuscript.

\section{Literature Cited}

Appelbaum, M. I., and E. M. Cramer. 1974. Some problems in the nonorthogonal analysis of variance. Psychological Bulletin 81:335-343.

Bocock, K. L., and O. J. Gilbert. 1957. The disappearance of leaf litter under different woodland conditions. Plant and Soil 9:179-185.

Bocock, K. L., O. J. Gilbert, C. K. Capstick, D. C. Turner, J. S. Ward, and M. J. Woodman. 1960. Changes in leaf litter when placed on the surface of soils with contrasting humus types. Journal of Soil Science 11:1-9.

Box, G. E. P. 1954. Some theorems on quadratic forms applied in the study of analysis of variance problems. II. Effects of inequality of variance and of correlation between errors in the two-way classification. Annals of Mathematical Statistics 25:484-498.

Brinson, M. 1977. Decomposition and nutrient exchange of litter in an alluvial swamp forest. Ecology 58:601-609.

Bunnell, F. L., and D. E. N. Tait. 1974. Mathematical simulation models of decomposition in tundra. Pages 207225 in A. J. Holding, O. W. Heal, S. F. Maclean, Jr., and P. W. Flanagan, editors. Soil organisms and decomposition in tundra. Tundra Biome Steering Committee, Stockholm, Sweden.

Cromack, K., and C. D. Monk. 1975. Litter production, decomposition, and nutrient cycling in a mixed hardwood watershed and a white pine watershed. Pages 609-624 in F. G. Howell, J. B. Gentry, and M. H. Smith, editors. Mineral cycling in southeastern ecosystems. United States Energy Research and Development Administration, Symposium Series CONF-740513, Washington, D.C., USA.

Curry, J. P. 1969. The decomposition of organic matter in soil. Part I. The role of the fauna in decaying grassland herbage. Soil Biology and Biochemistry 1:253-258.

Draper, N. R., and H. Smith. 1966. Applied regression analysis. John Wiley and Sons, New York, New York, USA.

Ewel, J. J. 1976. Litter fall and leaf decomposition in a tropical forest succession in eastern Guatemala. Journal of Ecology 64:293-308. 
Falconer, G. J., J. W. Wright, and H. W. Beall. 1933. The decomposition of certain types of fresh litter under field conditions. American Journal of Botany 20:196-203.

Fogel, R., and K. Cromack, Jr. 1977. Effect of habitat and substrate quality on Douglas fir litter decomposition in western Oregon. Canadian Journal of Botany 55:1632-1640.

Grigal, D. F., and J. G. McColl. 1977. Litter decomposition following forest fire in northeastern Minnesota. Journal of Applied Ecology 14:531-538.

Gustafson, F. G. 1943. Decomposition of the leaves of some forest trees under field conditions. Plant Physiology 18: 704-707.

Howard, P. J. A., and D. M. Howard. 1974. Microbial decomposition of tree and shrub leaf litter. I. Weight loss and chemical composition of decomposing litter. Oikos 25: 341-352.

Hunt, H. W. 1977. A simulation model for decomposition in grasslands. Ecology 58:469-484.

Jenny, H., S. P. Gessel, and F. T. Bingham. 1949. Comparative study of decomposition of organic matter in temperate and tropical regions. Soil Science 68:419-432.

Jensen, H. L. 1929. On the influence of carbon:nitrogen ratios of organic matter on the mineralization of nitrogen. Journal of Agricultural Science 19:71-82.

Lang, G. E. 1973. Litter accumulation through ecosystem development. Dissertation. Rutgers University, New Brunswick, New Jersey, USA.

Lawrey, J. D. 1977. The relative decomposition potential of habitats variously affected by surface coal mining. Canadian Journal of Botany 55:1544-1552.

Lousier, J. D., and D. Parkinson. 1976. Litter decomposition in a cool temperate deciduous forest. Canadian Journal of Botany 54:419-436.

Lunt, H. A. 1933. Effects of weathering upon composition of hardwood leaves. Journal of Forestry 31:43-45.

- 1935. Effects of weathering upon dry matter and composition of hardwood leaves. Journal of Forestry 33: 607-609.

Meentemeyer, V. 1978. Macroclimate and lignin control of litter decomposition rates. Ecology 59:465-472.

Melillo, J. M., J. D. Aber, and J. F. Muratore. 1982. Nitrogen and lignin control of hardwood leaf litter decomposition dynamics. Ecology 63:621-626.

Minderman, G. 1968. Addition, decomposition, and accumulation of organic matter in forests. Journal of Ecology 56:355-362.
Olson, J. S. 1963. Energy storage and the balance of producers and decomposers in ecological systems. Ecology 44:322-331.

Oohara, H., N. Yoshida, and N. K. Chang. 1971. Balance of producers and decomposers in a grassland system in Obihiro. Journal of Japanese Grassland Science 17:7-18.

Pal, D., and F. E. Broadbent. 1974. Kinetics of rice straw decomposition in soils. Journal of Environmental Quality 4:256-260.

Pinck, L. A., F. E. Allison, and M. S. Sherman. 1950. Maintenance of soil organic matter. II. Losses of carbon and nitrogen from young and mature plant materials during decomposition in soil. Soil Science 69:391-401.

Statistical Analysis System (SAS). 1979. SAS users guide. SAS Institute, Sparks Press, Raleigh, North Carolina, USA.

Snedecor, G. W., and W. G. Cochran. 1978. Statistical methods. Sixth edition. Iowa State University Press, Ames, Iowa, USA.

St. John, T. V. 1980. Influence of litterbags on growth of fungal vegetative structures. Oecologia 46:130-132.

Van Cleve, K. 1971. Energy- and weight-loss functions for decomposing foliage in birch and aspen forests in interior Alaska. Ecology 52:720-723.

Wieder, R. K. 1978. Decomposition of ${ }^{14} \mathrm{C}$ labeled fescue litter in Missouri strip mines. Dissertation. University of Missouri, Columbia, Missouri, USA.

Wieder, R. K., J. E. Carrel, J. K. Rapp, and C. L. Kucera. 1983, in press. Decomposition of tall fescue (Festuca elatior var. arundinacea) and cellulose litter on surface mines and a tallgrass prairie in central Missouri, U.S.A. Journal of Applied Ecology.

Wiegert, R. G., and F. C. Evans. 1964. Primary production and the disappearance of dead vegetation in an old field in southeastern Michigan. Ecology 45:49-63.

Witkamp, M. 1966. Decomposition of leaf litter in relation to environment, microflora, and microbial respiration. Ecology 47:194-201.

Witkamp, M., and D. A. Crossley, Jr. 1966. The role of arthropods and microflora in breakdown of white oak litter. Pedobiologia 6:293-303.

Witkamp, M., and J. S. Olson. 1963. Breakdown of confined and nonconfined oak litter. Oikos 14:138-147.

Woodwell, G. M., and T. G. Marples. 1968. The influence of chronic gamma irradiation on the production and decay of litter and humus in an oak-pine forest. Ecology 49:456465 . 